\title{
EL SACERDOCIO FEMENINO EN EL MUNDO FENICIO-PÚNICO ${ }^{1}$ FEMALE PRIESTHOOD IN THE PHOENICIAN AND PUNIC WORLD
}

\author{
por
}

ANA Ma JiMÉNEZ FLORES

\begin{abstract}
RESUMEN Revisamos con este trabajo el tema del sacerdocio femenino en la sociedad fenicio-púnica, partiendo tanto de las fuentes literarias clásicas y orientales como de los documentos epigráficos desde sus orígenes en el Levante hasta época cartaginesa. Creemos que los datos examinados sugieren la presencia casi obligada de mujeres en los ritos de fecundidad y su dirección en los cultos a divinidades de la fertilidad.
\end{abstract}

\begin{abstract}
In this paper we analyse the subject of the female priesthood in the Phoenician and Punic Society; it is re-examined the oriental and classical literary sources, as well as the epigraphical remains from its Oriental origins to the Punic Period. We suggest that the rites of fecundity needed the women's presence and the fertility cults have been presided by priestess.
\end{abstract}

Palabras claves Sociedad fenicio-púnica. Culto. Sacerdocio. Mujer.

Key words Phoenician and Punic Society. Cult. Priesthood. Woman.

La evolución de los estudios fenicio-púnicos ha conocido diversas vicisitudes según países y épocas. En el caso peninsular, el inicial impulso de la investigación basado esencialmente en la crítica de los textos clásicos fue pronto acompañado del trabajo de los arqueólogos, un avance en el que tiene mucho protagonismo la actuación del homenajeado, Dr. D. Manuel Pellicer. Las amplias posibilidades de investigación abiertas con sus descubrimientos y publicaciones contribuyeron a una diversificación e intensificación de los estudios, de la que se nutren ya varias generaciones de arqueólogos e historiadores. El trabajo que exponemos a

1. Este trabajo se engloba en las líneas de investigación desarrolladas por el Grupo de Investigación Religio Antiqua (Cód. HUM-650), de la Universidad de Sevilla. 
continuación no es más que la modesta aportación de quien reconoce la deuda contraída con la obra del Dr. Pellicer a lo largo de estos años.

Uno de los campos de análisis abiertos por aquellos hallazgos fue el de las expresiones religiosas. En un principio, dada la naturaleza de los materiales exhumados, el tema prioritario era el ritual y los comportamientos funerarios; pero desde muy pronto se plantearon interrogantes acerca de los espacios de culto y la prioridad de llevar a cabo estudios arqueológicos en los mismos ${ }^{2}$. Las dificultades implícitas en esta investigación son comunes a toda el área fenicio-púnica: hermetismo o confusión de las fuentes; escasez de excavaciones en lugares de culto o desaparición de los mismos durante la conquista romana; carácter disperso o esporádico de los objetos de culto... Estos obstáculos nos conducen con bastante frecuencia a volver la vista a multitud de fuentes de información: la arqueología, la epigrafía, la iconografía, la filología y la historia de las religiones. A pesar de estas contribuciones, el estudio de los cultos sigue siendo la gran asignatura pendiente en el ámbito de la religión fenicia, donde los avances arqueológicos, los descubrimientos literarios o los grandes epígrafes religiosos iluminan en la misma proporción que aportan dudas e interrogantes.

En relación con las manifestaciones de culto, hemos de fijarnos en la figura del sacerdote, el "ministro" del culto, en el sentido de administrador o ejecutante de las ceremonias y ritos. El personaje al que convencionalmente definimos como sacerdote detenta funciones y prerrogativas que se escapan con frecuencia a nuestra concepción del término, demasiado determinada por la herencia cultural propia. El sacerdote ejerce una doble función mediadora y transformadora: es representante de los hombres ante la divinidad y viceversa, está en contacto con ambos niveles, humano y divino, y su presencia canaliza y garantiza la comunicación entre ambos. Por otro lado, al ser "delegado" de la comunidad ante la divinidad, su asociación, trasposición y suplantación por parte de los representantes de ésta ante los hombres, ya sean miembros de la misma población o de otras entidades sociales, es una consecuencia casi irremediable.

En el contexto fenicio-púnico, hemos de iniciar nuestra indagación con los datos proporcionados por los textos ugaríticos. El principal ministro del culto es el propio monarca, al que acompañan los miembros de su familia, la reina y los "hijos del rey", preferentemente en el marco de los ritos dinásticos y de fertilidad. Centro y fuente de todos los poderes, incluso el religioso, la residencia real era escenario de las principales ceremonias. La distinción entre función política y religiosa es apenas perceptible y la generalización de un culto a los monarcas difuntos evidencia hasta qué-punto convergen ambas esferas (Caquot 1981: col. 348-349; Levine-Tarragon 1984). Los textos litúrgicos testimonian su presencia en todas las ceremonias, al menos en todas las ceremonias públicas, estando ausentes las menciones a otros sacerdotes u operarios del culto. La existencia de estos cargos y funciones nos es conocida por documentos de distinta naturaleza: textos administrativos, citas esporádicas en relatos literarios o correspondencia oficial. Se conoce la presencia de sacerdotes $(\mathrm{khnm})$, que constituían una corporación o grupo profesional perteneciente al personal de la casa real ( $b n \check{s} m l k$ ), bajo la dirección del $r b k h n m$, funcionario nombrado probablemente por el rey y de gran influencia en el reino. Al margen de éstos, se advierte la existencia de adivinos, $p r l n$, identificados con el barû mesopotámico (Gadd 1966, 26-34); los qdక̌m (sacerdotes, consagrados o esclavos) ${ }^{3}$, y una serie

2. A pesar de la superioridad que, en dicho campo, se otorgaba a los testimonios escritos sobre los materiales, en estos momentos se está produciendo una revisión de las posturas, en defensa de la complementariedad y especificidad de cada fuente (Laffineur 1988).

3. El confuso significado de este vocablo está en estrecha relación con su larga persistencia en el vocabulario religioso desde el II milenio a.C. hasta el periodo fenicio, contexto en el que aparece vinculado al ejercicio de la prostitución sagrada (Gruber 1986; 
de trabajadores, quizás de condición servil, dedicados a actividades especializadas (cantores, purificadores, tocadores de címbalos...) o a labores administrativas (escribas), y confundidos con el personal de servicio palatino. Se advierte, pues, una compleja jerarquía de funciones, cuya cúspide es detentada por el rey-sacerdote, y en la que se articulan actividades muy diversas. La presencia en los ritos de sacerdotes y auxiliares del culto es obligada, junto a especialistas con funciones específicas. Los sacrificadores, expertos en la preparación y descuartizamiento de las víctimas, o los adivinos, cualificados para la interpretación de los mensajes de la divinidad, bien por una predisposición natural o por una larga formación técnica (Oppenheim 1966: 37-39), desempeñan actividades muy concretas. Poco sabemos, en cambio, de la preparación y la cualificación de los sacerdotes. Cuando los documentos conocidos recogen el nombre y filiación de estos personajes nos señalan su parentesco o relación con el personal palatino, el alto funcionariado y la aristocracia local; su propia personalidad jurídica y económica es ya un indicio de su condición social destacada.

Durante la primera mitad del I milenio a.C. los reyes y miembros de la familia real de las ciudades fenicias podían ser sacerdotes. Es más, el rey se define como monarca de la ciudad y sumo sacerdote del dios "nacional", títulos que pueden ir asociados y transmitirse hereditariamente. Las menciones de los epígrafes ofrecen datos sobre las peculiaridades de esta relación en cada ciudad. En Sidón, los reyes detentan el sacerdocio de Astarté; mientras en Biblos, la monarquía se considera en ocasiones de "derecho divino". Yehawmilk afirma que la Señora de Biblos le ha hecho rey de la ciudad ('š $p^{c} l t n$ hrbt $b^{c} l t ~ g b l m m l k t^{c} l g b l$, $K A I 10,1-2)$ y, aunque en las inscripciones los reyes no llevan título sacerdotal, encontramos en el trono al hijo de un sacerdote de la Señora, ${ }^{c} \mathrm{Ozba}^{\mathrm{c}}$ al $(K A I 11)$, claro indicio de la estrecha vinculación del poder político con el citado cargo. Sobre Tiro no hay datos epigráficos pero Josefo recoge, citando a Menandro de Éfeso y Beroso, testimonios que indican el acceso al poder político de los sacerdotes, sin precisar si conservaban el título sacerdotal una vez que ocupaban el trono (Cont. Apion I, 123). La inquietud y los temores de Pigmalion respecto al poder de su tío Acherbas parecen, pues, bien justificados (Justino, XVIII, 4, 5-8 $)^{4}$. El mismo Flavio Josefo nos transmite también la noticia de la instauración de la fiesta de la égersis de Melqart por parte del monarca Hiram de Tiro, quien desde aquel momento asumiría el cargo de sacerdote del dios, transmitiéndolo a sus herederos (Cont. Apion I, 119). La intervención del poder civil se manifiesta a la vez en la construcción o reforma de templos (Elayi 1986: 254-255), documentada tanto en las fuentes literarias (Flavio Josefo, Cont. Apion I, 113-118 y Ant.Jud. VIII, 146-147) como en las epigráficas (KAI $4,7,10,14,15$ y 16). Bajo esta autoridad religiosa suprema, se constata la existencia de khnm y $r b$ khnm adscritos a divinidades y santuarios concretos, y la vida cultural y social de muchos de éstos deja entrever la pervivencia del entramado de funciones ya detectado en Ugarit. Uno de los documentos más ilustrativos es la inscripción doble de Kition (CIS 86A y B), en la que se recogen los salarios correspondientes al personal de servicio y de culto del santuario de Astarté(Masson-Sznycer 1972: 21-64, P1.IV-V). En este texto aparece un buen número de funcionarios y servidores, que desarrollan en las instalaciones del templo actividades tanto de culto como de mantenimiento y aprovisionamiento (porteros, cantores, obreros, sacrificadores, panaderos, barberos, prostitutas, pastores).

Bonnet 1988: 111 ss.). Es muy probable que a lo largo de este tiempo y el paso de un contexto cultural a otro el término haya conocido alteraciones en su significado, relacionándose con funciones distintas a las originarias; es más, las referencias bíblicas a estas figuras religiosas, con residencia en el templo ( 2 Re 23,7), se manifiestan en un tono oscuro, que apenas aclara nada (Olmo 1995: 293-294).

4. En opinión de E. Lipinski, el contexto histórico en el que se desarrollan estos hechos corresponde al periodo helenístico, en una fase en la que el papel de mqm ' $l m$ desempeñado por el sacerdote de Melqart sería tan importante o más que la función real (1995: 455). Esta propuesta parece ignorar la alta cronología de la fundación, constatada por los hallazgos arqueológicos, y la existencia del cargo sacerdotal desde el s. IX a.C., adscrito en un principio a la familia real. 
El panorama cambia sustancialmente con respecto a las ciudades-estado occidentales, aunque en el fondo vemos reproducirse de nuevo la misma relación poder civil-poder religioso. Como depositaria de la autoridad de la comunidad es la asamblea de ciudadanos quien vela por la integridad de las instalaciones religiosas y el estricto cumplimiento de las normas litúrgicas ${ }^{5}$. En casos más concretos, la asamblea designa comisiones o colegios de magistrados encargados de analizar cuestiones puntuales de ámbito religioso, como las comisiones elegidas para la redacción de las tarifas sacrificiales, collegium decemviri qui super res sacras $\mathrm{o}^{c} \breve{s} r t h{ }^{\prime} \check{s}^{\prime}{ }^{\prime} \check{s}^{c} l h m q d \check{s} m$ (CIS I, 165 y 3917) ${ }^{6}$. Sin embargo, para el ejercicio de los cargos y funciones no corporativas, desempeñados por un solo individuo, se recurrirá a la selección de miembros destacados de la comunidad, sobre todo aquellos que, por sus cualidades morales o su origen, mejor se avienen a los requisitos de un cargo representativo tan relevante. A estas funciones quedan vinculados, desde un principio, los altos magistrados, los sufetes y rabs (Huss 1993: 309-311). Serán éstos quienes detenten los sacerdocios más notables, perpetuándose en ocasiones en el seno de la misma familia, y desempeñando un papel central en las ceremonias litúrgicas más trascendentales. Según Justino $(X V I I I, 7,9)$, el hijo del general Malco ejercía el sacerdocio; las inscripciones púnicas, tanto votivas como funerarias, muestran la concentración de cargos públicos $(\check{s} p t, r b)$, en individuos o familias que, a su vez, desempeñan el sacerdocio o sumo sacerdocio ( $k h n, r b k h n m)$ o actúan como mqm' 'lm o mqm'lmmtrh 'štrny (CIS I, 4864-70 y 5903) en la celebración de la égersis del dios ${ }^{7}$, probablemente la ceremonia de mayor trascendencia en el año litúrgico. Poco más sabemos acerca de la elección de estos cargos sacerdotales, si ésta se realizaba dentro de un colegio sacerdotal o bien las funciones se distribuían según el rango familiar oel cursus honorum, aunque el elemento hereditario parece determinante a tenor de las múltiples referencias a cargos religiosos transmitidos de padres a hijos ${ }^{8}$. El grupo sacerdotal se presenta, pues, como un conjunto jerarquizado de individuos, pertenecientes a las más altas esferas sociales y políticas, dedicados al ejercicio del culto de forma temporal, intercalada con la función administrativa y política o con posterioridad a la misma, y, por tanto, de carácter más representativo que profesional. Al igual que en el caso de la monarquía, los representantes de la comunidad, elegidos expresamente por la asamblea del pueblo, ' $m$ (Sznycer 1975), son los intermediarios más adecuados para presidir los actos religiosos públicos que repercuten en la totalidad del grupo social y los individuos de mayor disponibilidad laboral y cultural para las exigencias de la función.

Otra cuestión serán las ceremonias de culto privado, para las que cada santuario o templo contará con personal cualificado, formado profesionalmente en la misma institución. Nos falta para el mundo cartaginés un documento como la inscripción chipriota, aunque los epígrafes votivos del tofet y los funerarios suplen en parte esta carencia; en ellos aparecen como oferentes sacrificadores o $z h h$ (CIS 165) y jefes de sacrificadores

5. El decreto de la asamblea de Gozzo, Malta (CIS I, 132), destinado a la restauración de los templos de la ciudad documenta esta responsabilidad; aunque la preocupación religiosa va pareja de la tutela del erario público.

6. Tampoco en este caso está ausente la preocupación por la regulación de los intercambios económicos que subyacen en el desarrollo de las ofrendas (Ribichini 1985; Xella 1985).

7. El título aparece en una veintena de inscripciones, y entre ellas la inscripción CIS I, 5980 (= RES 1569) cita expresamente al $m q m$ ' $I m$ lml(qr)t, lo que apoyaría la idea de que se trata del despertador o resucitador de Melqart. Es sintomático, según C. Bonnet, el hecho de que el teónimo dominante en la onomástica de estos personajes es Melqart (1988: 174-179), lo que incidiría además en la vinculación de la función con familias y grupos sociales concretos que destinarían a sus descendientes, desde la cuna, para este cargo.

8. Los intentos por determinar los distintos elementos de esta jerarquía permiten señalar algunas figuras relevantes: el $r b k h n m$, jefe de los sacerdotes, los khnm o sacerdotes y los $\breve{s}$ ' (CIS I, 359), definidos como sacerdotes de segundo rango (Gsell 1929: 396-397). Se transmiten todos los grados de la escala jerárquica: CIS I, 3788 para el rb khnm; en CIS I 4858 encontramos un sacerdote hijo de sumo sacerdote; y en CIS I 4859 tenemos un $s n$ ', hijo y nieto de sumos sacerdotes. El cargo de rb mqm ' $l m$, también conocido en la epigrafía cartaginesa, puede quedar reservado a una familia concreta (CIS I, 377), y algo similar podemos apuntar de los sacrificadores (CIS I, 3354). 
(CIS I, 3354), señalando una organización jerárquica similar a la de los sacerdotes ${ }^{9}$, siervos del templo, ${ }^{c} b d b t$, con referencias a la divinidad titular del $\operatorname{mismo}^{10}(C I S 250,252,254-55,3779,4834-40,4844,4894$, 5145, 5594, 5657, 5682-83), porteros (Fantar 1973: 262-264; Garbini 1986: 53) y adivinos (Mariotti 1991: 714-716). Las citadas tarifas sacrificiales mencionan la presencia obligada en cada ceremonia de un sacerdote y un sacrificador (CIS I, 165, 168-169, 175 y 3917; Février 1948; Xella 1985: 42-43), cuya dedicación laboral debía ser de tiempo completo o, al menos, durante la mayor parte del año, y a los que se destina parte de la ofrenda, además de un pago en metálico para los primeros.

La vinculación del sacerdocio con la monarquía o las aristocracias urbanas conlleva la participación en este ejercicio de los miembros femeninos de la familia real o la nobleza. Las inscripciones reales dejan entrever que la mujer no estaba relegada al papel de simple espectadora o devota, una simple auxiliar pasiva del culto. Como su predecesora la reina ugarítica, las mujeres de las casas reales fenicias desempeñan actividades religiosas: promueven la construcción de templos y el culto, actividad bien ilustrada por la actuación de Jezabel, hija de Ithobaal de Tiro ( $\operatorname{Re} 16,33 ; 2 \operatorname{Re} 10,26)$, y ejercen el sacerdocio de divinidades femeninas tutelares. La inscripción de Eshmunazor II de Sidón cita a la madre de éste, Umm ${ }^{c}$ Astarté, como sacerdotisa de nuestra señora Astarté (CIS I, $3=K A I 14)$; sin embargo, en la inscripción de Eshmunazor I y Tabnit, antecesores del citado monarca, el sacerdocio de Astarté era detentado por el rey. Desde este momento se produce una ruptura en la tradición hereditaria, de tal forma que el cargo no vuelve a ser asumido por los herederos del trono. J. Elayi interpretó este hecho como resultado de la supresión del título durante la minoría de Eshmunazor II por su madre, quien, por razones que desconocemos, se lo reservó en exclusividad. C. Bonnet (1996: 33) presupone que a la muerte de Tabnit, el cargo fue heredado por su esposa, sin llegar a transmitirlo a sus herederos. Respecto a la cuestión de la participación de las mujeres de la casa real en las funciones tutelares ejercidas por el trono es paradigmática la figura de Dido; la legendaria fundadora de Cartago se erige desde el primer momento no sólo en directora de la expedición de exiliados sino que, además, detenta las prerrogativas religiosas de un jefe supremo. En este sentido, cumple con el cometido "regio" de proteger los cultos (Elayi 1986: 255-257), propiciando su celebración periódica y presidiendo los ritos más importantes (Justino, XVIII, 4, 15), y cuando acoge en su expedición al sacerdote chipriota, en última instancia está preservando el mantenimiento de la piedad religiosa tradicional entre la nueva comunidad (Justino, XVIII, 5, 2). Según una tradición recogida por Justino y Silio Itálico, Dido sería, después de muerta, honrada como diosa (XVIII, 6, 8: Quam diu Karthago invicta fuit, pro dea culta est), contando con un templo situado en el centro de la ciudad (Pun. I, 81-92 y 97-98). Dado el carácter casi mítico y legendario del relato, en esta figura femenina se encarnan las virtudes piadosas atribuidas a un monarca fundador; no es posible determinar si las prerrogativas religiosas asumidas por la princesa tiria se deben a su pertenencia a la casa real o son heredadas de su esposo, o, lo que resulta bastante probable, por ambas circunstancias a la vez.

Fuera del ámbito palatino y aristocrático es más arduo precisar la existencia de sacerdocio femenino: la desaparición de los archivos palatinos y la escasez de inscripciones privadas nos dejan un bagaje documental muy precario. No obstante, contamos con un documento excepcional: una crátera de la necrópolis de Sidón,

9. Los epígrafes neopúnicos $K A I 120,121$ y 126 recogen los términos ${ }^{c} z r y{ }^{\prime} d r^{c} z r m$ para hacer referencia a estos funcionarios, que en los tex tos cartagineses aparecían como $r b z b h m$, expresiones que en las versiones latinas se traducen como praefecti sacrorum o flamines (Rey Coquais 1987; Lipinski 1995: 460-462).

10. Este dato nos obliga a excluir todas aquellas menciones en las que el fiel se declara siervo de una divinidad genérica, respondiendo a una situación de servidumbre real o figurada, en tanto devoto de esa figura divina (CIS I, 256). 
empleada como urna funeraria, con una inscripción doble. El epígrafe cita a Geratmilk, sacerdotisa de Astarté $\mathrm{Hr}$ (Puech 1994). En el texto no hay referencia alguna a su filiación, ni siquiera el personaje encargado del piadoso acto del sepelio, incluida la redacción del epígrafe, menciona ningún vínculo de parentesco con la difunta. Acerca del antropónimo, E. Puech señala que grtmlk, cliente de Milk (Heltzer 1987; Halff 1963-64: 105-106; Ferjaoui 1993: 303-316), está escasamente testimoniado y en dos de los tres casos femeninos conocidos el nombre corresponde a sacerdotisas al servicio de Astarté, quizás dedicadas a la prostitución sagrada (Puech 1994: 52-53). Nos encontramos, pues, ante una "especialista" del ceremonial, aunque sin saber en qué tipo de ritos participaba, adscrita al culto de una divinidad muy concreta (Xella-Bonnet 1996; Bonnet 1996: 30-31) en cuyo santuario residiría, dedicándose de por vida a esta actividad. La ausencia de menciones sobre cónyuges o descendientes puede entenderse como consecuencia de la exclusividad de la función o la juventud de la difunta; mientras la omisión de la filiación señalaría un origen humilde o servil. Todos estos datos nos remiten a la amplia tradición mesopotámica relativa a la presencia de personal femenino al servicio de los templos y santuarios, un substrato cultural al que no son ajenas las instituciones cananeas.

La tradición literaria mesopotámica ilustra ampliamente la existencia de mujeres en el ámbito templar dedicadas a tiempo completo al ejercicio del culto. Partiendo de la clasificación de J. Renger, P. Negri Scafa ofrece otra división tripartita basada en la función, al margen de su condición servil o libre: personal ligado al culto; personal ligado a la administración y, por último, personal dedicado al mantenimiento de las actividades internas (Negri Scafa 2001: 395). Dentro del personal femenino del primer grupo, donde deben situarse las sacerdotisas, entendidas como "administradoras" del culto, según precisamos en un principio, encontramos ocho categorías: entum, ugbatum, naditum, šugitum, qadištum, kulmasitum, harimtum y kezertum. La mayor parte de la actividad de este personal femenino se desarrollaba en el gagum o claustro, lugar de residencia de las naditu, con algunas excepciones, qadištu y kulmašitu, acompañadas probablemente de las esclavas o figuras de condición servil (harimtu, kezertu). Esta diversidad es reflejo de las diferentes funciones y su mayor o menor prestigio social, lo que conlleva cierta importancia política y la independencia económica.

A partir de los inicios del Hierro, con el colapso del sistema palatino, las instituciones de esta naturaleza quedan confinadas a los santuarios y templos, cuyo modelo sería transmitido desde la costa sirio-palestina (Yon 1995) a Chipre (Kition) y otros puntos del Mediterráneo, en los que se instalan grandes centros religiosos (Erice). Paralelamente, la documentación se vuelve escueta, reducida sólo a epígrafes votivos o funerarios, debido en buena medida a la generalización del papiro y la escritura alfabética como medio de redacción. A menor escala, cada centro religioso debió contar con personal propio dedicado a las actividades de culto de la divinidad titular y vinculado expresamente al templo. Éstos son los individuos que se presentan en las inscripciones como ${ }^{c} b d / /^{c} m t$ bt $X$., "siervo/a del templo de X..".

$\mathrm{Al}$ aproximarnos, pues, al desarrollo del sacerdocio femenino en Occidente deberemos tener en cuenta la existencia, por una parte, de "profesionales del culto", formadas y especializadas en la liturgia, y por otra, de altos sacerdocios femeninos, detentados por mujeres de la aristocracia urbana, cuya vocación les viene dada por nacimiento. Para documentar estas figuras hemos de remitirnos esencialmente a la epigrafía, bastante abundante en Cartago. En la ciudad norteafricana los mayores centros de información se localizan en el tofet y en la necrópolis, sobre todo la de Santa Mónica o de los Rabs (Benichou-Safar 1982: 32-33). En el primer caso, es notable el alto grado de representatividad social de las inscripciones del santuario; el elevado número de epígrafes, con referencia frecuente a la filiación y extracción social de los oferentes, presenta un amplio espectro de categorías y grupos sociales. Entre éstos se incluyen las mujeres, de origen y condición diversa, fenómeno al que M.G. Amadasi ha dedicado un estudio (1988). Pero no debemos ilusionarnos con estas perspectivas. De 3747 inscripciones conocidas, sólo 406 pertenecen a mujeres, un $10 \%$ del total aproximadamente, y únicamente en 54 casos el estado del texto permite reconocer el nombre completo de la dedicante, citada con su patronímico y genealogía, con el nombre de su marido y el patronímico de éste, o con ambos (eadem 1988: 144-145). 
El primer dato que sorprende al iniciar la lectura de los epígrafes del tofet es la ausencia de dedicatorias de sacerdotisas. Las mujeres relacionadas con el culto o el ámbito religioso que encontramos se califican de siervas o devotas. A esta categoría pertenecen cuatro inscripciones de lectura segura. Cada una de ellas hace referencia a diversas divinidades. En CIS I, 253 la dedicante se declara sierva del templo de Hathor Miskar ( ${ }^{c} b d b t$ htrmskr); en esta categoría podríamos incluir con ciertas reservas una inscripción fragmentaria donde no se puede determinar si la mención del templo hace referencia al centro de trabajo de la oferente o su progenitor (..b]bt ${ }^{c} \check{s} t r t ~[b . .$, en] el templo de Astarté [en.., CIS I, 5547). En los casos restantes no conocemos el establecimiento religioso: sierva de los dioses (' $m t$ ' $l m, C I S$ I, 378), sierva de Tanit (' $m$ tnt, $C I S$ I, 2632) y sierva de Astarté de Érice ( ${ }^{c} m t \check{s}^{c} \breve{s} t r t '{ }^{\prime} r k, C I S$ I, 3776). Esta última dedicante presenta una genealogía de matronímicos, dato que sugiere una posible filiación al santuario o al culto específico de la divinidad titular del mismo, quizás en condición servil, y su dedicación a actividades de prostitución sagrada (Amadasi 1988: 146; Jiménez Flores 2001: 21) ${ }^{11}$. No son éstas las únicas dedicatorias realizadas por mujeres vinculadas al templo; en Kition encontramos una inscripción correspondiente a la ofrenda de una estatua a Astarté realizada por la esposa de un siervo del templo de la diosa (CIS I, $11=K A I 33$ ).

La ausencia de sacerdotisas en esta documentación podría entenderse como una exclusión, por motivaciones ideológicas que se nos escapan, de los ritos practicados en el tofet, o bien como una simple consecuencia del azar en los hallazgos y la conservación de los textos. En este sentido, hemos de citar las menciones de sacerdotisas en el tofet de El-Hofra, también en la costa africana, con una datación en el s. III a.C. La inscripción $n^{\circ} 67$ del citado santuario corresponde a 'Arišat, jefa de las sacerdotisas o suma sacerdotisa ( $r b h k h k t$; Berthier-Charlier 1955: 64, pl. XIV, C); de forma indirecta aparece también en la inscripción $\mathrm{n}^{\circ} 72$. El dedicante es un hombre, reconocido por su matronímico, hijo de Hamilky, la sacerdotisa ( $h k^{c} n t$, Berthier-Charlier 1955: 66, pl. XIV, D).

El segundo conjunto de inscripciones corresponde a los epígrafes funerarios, procedentes en su mayoría de la necrópolis de Santa Mónica, que recogen un buen porcentaje de titulares con esta categoría profesional, rasgo que ha dado pie a la calificación de necrópolis de los Rabs, Sacerdotes y Sacerdotisas. Las menciones de sacerdocio femenino, aunque menos abundantes que las de sus homónimos masculinos, revisten gran importancia ya que en la mayoría de los casos se conserva buena parte de la filiación de la difunta y su esposo, cuando lo tiene, informándonos sobre su extracción social y origen, amén de los posibles datos sobre la actividad realizada. Las inscripciones más escuetas corresponden a mujeres definidas como $h \mathrm{khnt}$, la sacerdotisa, título que puede citarse tras el patronímico o antepuesto al mismo. El esquema quedaría, pues, como sigue: $X$ bt $Y h k h n t$ ' 'st $Z$, "X hija de $Y$ la sacerdotisa, esposa de $Z$ ". De los casos documentados, contamos con un ejemplo en el que sólo aparece el patronímico, sin referencia a ningún cónyuge ( $C I S$ I, 5947); la ausencia de datos sobre la edad de la difunta no permite determinar si este celibato se debía a su corta edad o era una condición social intencionada. En otros casos es el patronímico el elemento omitido (CIS I, 5941), lo que podría denotar un origen humilde o servil de la titular; en este ejemplo, además, apenas hay alusiones a los cargos o actividades del esposo. Sin embargo, lo más frecuente es encontrar la filiación de ambos esposos (CIS I, 5979 y 5994). El texto más ilustrativo corresponde a CIS I, 5950, donde la difunta se presenta con sus patronímicos y los de su marido, perteneciente a una familia de la alta aristocracia; detenta los títulos de sufete y jefe de sacerdotes, los mismos cargos que desempeñó su padre, y a los que se suma su participación en la principal fiesta religiosa de la ciudad en calidad de mqm 'lm mtrh ‘štrny (Bonnet 1988: 175).

11. Según C. Bonnet, la expresión recogida en un epígrafe cartaginés (CISI, 263) acerca de una congregación de Astarté estaría haciendo alusión también al grupo de mujeres dedicadas a esta actividad $(1996,99)$. 
Sobre la jerarquización dentro del cuerpo sacerdotal femenino algunos epígrafes nos señalan la existencia de sumas sacerdotisas, $r b$ khntm. En CIS I, 5949 la suma sacerdotisa se presenta con sus patronímicos hasta la tercera generación, en un alarde de exhibición de su elevado origen; la fractura de la estela impide saber si se seguía la misma tónica en el caso del esposo, suponiendo que estuviera casada. Esta intencionalidad es más evidente en la inscripción CIS I, 5988, en la que la difunta señala el ejercicio de un alto cargo por parte de su padre, $r b$, mientras su esposo ejerce la función de sufete, en consonancia con la actividad desarrollada por sus antecesores, sufetes también. En algunos textos se hace mención igualmente de la divinidad a la que rinden servicio. Las alusiones raramente son explícitas y dejan muchas dudas acerca de la identidad de estas figuras divinas. El epígrafe más extenso, aunque procedente de Cartago, fue localizado en Avignon y corresponde a una "sacerdotisa de Nuestra Señora" ( $h k h n t \check{s} r b t n$ ), título al que acompaña el patronímico, el nombre del esposo y su filiación, mencionando el ejercicio de la función de $m q m$ ' $l m$; como sacerdotisa de la misma divinidad conocemos a otra mujer, Grmlqrt (CIS I, 5942; RES 7), que, sin embargo, no hace referencia alguna a su origen o a su esposo. El único caso explícito en el que conocemos la divinidad a la que se rinde servicio es la inscripción CIS I, 5987, procedente de la necrópolis de Ard el-Kheraib y cuya titular es sacerdotisa de Koré, $h k h n t s ̌ k r w^{c}$ (Benichou-Safar 1982: 216-217, $\mathrm{n}^{\circ} 49$ ). Sabemos por Diodoro Sículo que, cuando se introdujo en Cartago el culto a las dos diosas, Deméter y Koré, se designaron para su sacerdocio a personas notables y de elevada moral $(X I V, 77,5)$, entre las que debieron incluirse mujeres para los sacerdocios femeninos, rasgo peculiar que caracterizará este culto hasta época romana (Lipinski 1995: 379-380).

Salta a la vista el contraste entre los datos epigráficos, donde figuran mujeres participantes en casi todas las escalas del servicio cultual, y los textos litúrgicos, donde es un lugar común la ausencia de menciones femeninas. En algunos cultos, como el de Melqart, un precepto cultual las excluye del santuario de Gadir (Sil.Ital., Pun. III, 21-22); y en otros, como el de Saturno Africano no se menciona a ninguna sacerdotisa, a pesar de la presencia de mujeres en las representaciones de las estelas, bien como dedicantes o como portadoras de los signos de iniciación o atributos de vestimenta sacerdotal (Leglay 1966: 375, n. 5). Las imágenes pueden servirnos también de fondo documental. En este sentido, a través de las iconografías de las terracotas, especialmente las ibicencas, se constata la alta valoración de la mujer como símbolo divino; se tiene constancia de su participación en los actos rituales como orantes, posibles sacerdotisas, auletrices y timpanistas. Entre las representaciones femeninas conocidas los estudios iconográficos tradicionales incluyen como sacerdotisas varias figuras. La primera de estas imágenes corresponde al frontón de una estela del tofet ( $\mathrm{Cb} 687$ bis), acompañada de inscripción votiva (CIS I, 5780), donde aparece una mujer esculpida en bajorrelieve, con la pierna derecha flexionada en tierra, los cabellos sueltos sobre la espalda, vestida de túnica corta y los pies desnudos, y la mano derecha alzada realizando una libación, mientras la mano izquierda se apoya en un montículo. La estela se data entre fines s. III y principios II a.C. A pesar de haberla presentado como sacerdotisa en su clasificación, C. Picard aseguró que esta enigmática imagen reproducía el modelo del guerrero vencido que implora a su vencedor, recordando el arquetipo de la amazona vencida del Pintor de las Nióbides del Museo de Palermo (Picard 1973-74: 126-127, Pl. VII, 6). Sintetizando las opiniones vertidas acerca del significado de esta imagen, J. Debergh señala dos posibilidades: o bien es la figuración de una escena mitológica, tomada de la iconografía griega y adaptada a modelos púnicos; o bien es el testimonio ilustrado de una ceremonia de libación, expresado a través de una estética helenizante (1976, 107-112).

Más próximas a la realidad del culto pueden ser las representaciones con mujeres ataviadas de larga túnica. En otra estela votiva del tofet de Salambo datada en la segunda mitad del s. III a.C. encontramos una escena de ofrenda, encuadrada por dos columnas, un altar de sacrificios con una cabeza de toro en su extremo superior y una mujer vestida de amplia túnica con la mano derecha alzada en gesto de adoración y una píxide en la mano izquierda. La inscripción (CIS I, 3347) corresponde al sacrificio realizado por una 
sacerdotisa o hieródula, dado que la dedicante se presenta con sus matronímicos ${ }^{12}$. Han sido identificados con figuras sacerdotales los personajes con estola reproducidos en las estelas (Cecchini 1981), aunque en su mayoría las representaciones son masculinas; sólo se han adscrito como femeninas dos figurillas de terracota de Ibiza que, a juicio de S.M. Cecchini, son bastante dudosas, y una tercera imagen de Cartago (Cecchini 1981: 30, n. 38), ésta última perteneciente a una figura femenina sentada con estola. Sí es más segura la representación del sarcófago de mármol procedente de la necrópolis de Santa Mónica; a pesar del regusto helenizante que domina la ejecución plástica se aprecian algunos rasgos significativos como las reminiscencias egipcias, centradas en las alas que cubren la parte inferior del cuerpo o la peluca en forma de halcón. De inspiración púnica son los atributos que porta la imagen en su mano, un incensario en forma de paloma. La complejidad del conjunto resta verosimilitud a la figura sacerdotal y transforma a la difunta en una "transfiguración" de la propia divinidad a la que sirve y con la que se identifica.

Este papel secundario en los programas iconográficos sería consecuencia de la propia marginación económica y "social" de la vida pública, que relegaba a las mujeres a símbolos religiosos vinculados a cultos "femeninos" o a simples oferentes; a la mujer púnica se le reconoce la suficiente personalidad como para poder participar en los misterios sacros, una participación que podría ser necesaria en algunos cultos por exigencia de su sexo (Griñó 1991: 597). Se le otorga el papel genérico de oferente, especialmente evidente en la producción de exvotos, pero sin ocupar un puesto equiparable al de sus compañeros masculinos. Resulta sintomático el predominio de imágenes masculinas en la producción más monumental de estelas figuradas (Bisi 1965), mientras las femeninas se concentran en productos votivos más modestos, como terracotas y figurillas de barro. Las producciones de exvotos en terracota denotan desarrollos locales muy concretos, que pueden hacer alusión a realidades cultuales propias. Las figuraciones pueden ser reflejo de los ritos o arquetipos esquematizados de las divinidades a las que van dirigidos; en algunos casos, el predominio de la figura femenina estaría señalando la rélación de las mujeres con dicho acto que, en algunas circunstancias, podrían organizarse en cofradías o asociaciones de culto, como la "comunidad del incienso" o la "comunidad del caduceo" (Picard 1976: 173; Garbini 1986: 45).

R. A. Henshaw, en su análisis del papel femenino en la religión hebrea, y por extensión en todo el Próximo Oriente, expone con claridad la idea determinante: la mujer está llamada a simbolizar la sexualidad en el culto (1994: 7). El objetivo último de los cultos será la fertilidad, de ahí su dedicación casi absoluta a la divinidad por antonomasia de la fecundidad ${ }^{13}$ : Astarté. La sexualidad femenina se manifestará a través de dos prácticas: la prostitución sagrada y la hierogamia o matrimonio sagrado. Ambas prácticas cuentan con una gran tradición en Próximo Oriente y siguen vigentes en las prácticas religiosas púnicas. La prostitución sagrada ha sido documentada en casi todo el mundo mediterráneo (Yamauchi 1973; Jiménez Flores 2001), trascendiendo incluso el marco cultural oriental para implantarse también en contexto griego o romano. Un reflejo de esta práctica en la epigrafía se detecta en el empleo de matronímicos tanto en Oriente (KAI 29; Garbini 1990) como en Occidente (Verger 1965); en la inscripción $n^{\circ} 72$ de El-Hofra la progenitora detenta el cargo de sacerdotisa, lo que podría sugerir una jerarquía entre estas servidoras. Como indicio adicional de esta actividad podemos añadir los datos proporcionados por la onomástica, con un evidente predominio de los nombres teóforos formados con términos alusivos a la condición servil o de dedicación: Grtmlqrt, Grtmlk, 'Mtštrt, 'Mtmlqrt. Estos nombres pudieron ser otorgados desde el mismo nacimiento, especialmente en el caso de las hijas de hieródulas o personal del templo, o bien fueron adoptados tras

12. E. Lipinski recuerda la celebración de un rito de entronización de una sacerdotisa con una ofrenda similar documentado en Emar (1987: 171-172, figs. 5-6).

13. Esto no implica que no hubiera sacerdotes masculinos dedicados al culto de divinidades femeninas; así conocemos un sacerdote de 'Alat (CIS I, 4861) y otro sacerdote de Astarté (CISI, 4862). 
un periodo de iniciación o formación, en el caso de los miembros de la alta aristocracia o las sacerdotisas dedicadas a cultos muy específicos, como el de "Nuestra Señora" o Koré.

Junto a Astarté, las dos diosas, Deméter y Koré, desempeñan un papel similar circunscrito al ámbito agrario. De igual manera, el papel simbólico atribuido por la mujer en los cultos agrícolas es altamente significativo. En el culto de Ceres, de gran tradición en la feraz región agrícola norteafricana, Tertuliano recuerda la consagración en régimen de celibato de sus sacerdotisas (Tertul., De castitate 13), mientras la inscripción neopúnica de ${ }^{\mathfrak{c}}$ Ayin Zakkar, nos indica la larga dedicación, casi de por vida, de la suma sacerdotisa (Ferjaoui 1996). Sin embargo, no podemos pasar por alto que el culto de las diosas es una importación del siglo IV de origen griego, que, aunque punicizada, responde a las prerrogativas ideológicas y religiosas de otra cultura. Para conocer la trascendencia del papel femenino en el rito púnico habrá que centrarse en cultos plenamente orientales. El ejemplo más elocuente del valor simbólico y presencial de la mujer estaría reflejado en la celebración de la fiesta religiosa púnica más notable, la égersis de Melqart. Los ritos celebrados conllevan la realización de una hierogamia, recogida en el título de "esposo de Astarté" que acompaña al tradicional $m q m$ ' $l m$, en la que participaría una alta figura sacerdotal femenina, probablemente la suma sacerdotisa de la diosa. La inscripción de Avignon deja suponer que la unión sagrada incluso podría ser realizada por cónyuges en ocasiones excepcionales.

Las conclusiones de R.A. Henshaw para el Próximo Oriente parecen ser válidas también para el contexto púnico. En la división que propone para el personal de culto, con cinco grupos diferenciados según su participación en los ritos ${ }^{14}$, destaca la preponderancia del elemento femenino en el cuarto grupo, dedicado a los cultos de fertilidad y la sexualidad (Henshaw 1994: 191-270), con una distribución equilibrada en los demás grupos, donde se conocen homólogos femeninos y masculinos, y la exclusión de algunas funciones del primer grupo, como el sacrificio de animales. El examen de la documentación epigráfica púnica ha permitido constatar la participación femenina y su presencia en los actos cultuales, supeditada a dictados ideológicos similares. Como símbolo sexual, vehículo de fertilidad, los ritos de fecundidad serán su campo de actuación preferente, teniendo que estar necesariamente presente en éstos, presidiendo o ejecutándolos personalmente. Esta participación se articula y especifica de acuerdo con la jerarquía interna de cada función que, a su vez, reproduce el propio orden social de la comunidad.

14. Al primer grupo corresponden los altos funcionarios o funcionarios jefe, que emplean las palabras litúrgicas y ejecutan los sacrificios y ofrendas; en el segundo se incluyen los cantantes, plañideras, músicos y bailarines; los magos, adivinos y profetas integran el tercer grupo; en cuarto lugar, aparecen los oficiantes relacionados con la sexualidad y los cultos de fertilidad; y por último los oficiantes auxiliares (Henshaw 1994: 4). 


\section{BIBLIOGRAFÍA:}

AMADASI GUZZO, M.G. (1988): "Dédicaces de femmes de Carthage", Karthago. Studia Phoenicia VI. OLA 26: 143-149. Leuven.

BISI, A.M. (1965): "La religione punica nella rappresentazione figurate delle stele votive", SMSR XXXVI: 99-157.

BONNET, C. (1988): Melqart. Cultes et mythes de l'Héraclès tyrien en Méditerranée. Studia Phoenicia VIII. Leuven.

- (1996): Astarté. Dossier documentaire et perspectives historiques. Roma.

CAQUOT, A. (1981): “Rephaïm”, Supplément au Dictionnaire de la Bible, fasc. 55: 344-357.

CECCHINI, S.M. (1981): "Motivi iconografici sulcitani: una scena cultuale e i personaggi con "stola", Vicino Oriente IV/ 2: 13-32.

DEBERGH, J. (1976): "Image grecque, interpretation carthaginoise", Homenaje a García Bellido I. Revista de la Universidad Complutense XXV, $n^{\circ}$ 1: 91-112. Madrid.

DELCOR, M. (1979): “Le personel du temple d`Astarté à Kition d après une tablette phénicienne”, UF 11: 147-164.

ELAYI, J. (1986): “Le roi et la religion dans les cités phéniciennes à l'époque perse”, Religio Phoenicia. Studia Phoenicia IV: 249-261. Namur.

FANTAR, M.H. (1973): "Récentes découvertes dans les domaines de larchéologie et de l'épigraphie puniques", $B A C$ ns. 7, 1971: 262-264.

FERJAOUI, A. (1993): Recherches surles relations entre l'Orient phénicien et Carthage. OBO 124. Friburg.

_ (1996): "Une épitaphe néopunique d une grande prêtresse de Cérès provenant de "Ayin Zakkar (Tunisie)", Semitica 46: 25-35.

FÉVRIER, J.G. (1948): “Magistratures et sacerdoces puniques”, Revue d Assyriologique XLII, n 1-2: 83-88.

GADD, C.J. (1966): "Some Babylonian Divinatory Methods and their Inter-relations", La divination en Mésopotamie Ancienne et dans les régions voisines: 21-34. Paris.

GARBINI, G. (1986): Venti anni di epigrafia punica nel Magreb (1965-1985). RSF 14 Suppl. Roma. (1990): "L`ancella del signore", RSF XVIII, 2: 207-208.

GRIÑÓ FRONTERA, B. (1991): "La mujer en las terracotas púnicas de Ibiza: aspectos iconográficos", G. Duby-M. Perrot eds., Historia de las Mujeres. La Antigüedad: 587-597. Madrid.

GRUBER, M.I. (1986): "Hebrew q desah and her Canaanite and Akkadian Cognates", UF 18: 133-148.

GSELL, St. (1929): Histoire Ancienne de l'Afrique du Nord IV. Paris.

HALFF, G. (1963-64): "L'onomastique punique de Carthage”, Khartago 12: 61-146.

HELTZER, M. (1987): "The ger in the Phoenician Society", E. Lipinski ed., Phoenicia and the East Mediterranean on the First Millenium B.C. Studia Phoenicia V: 309-314. Leuven.

HENSHAW, R.A. (1994): Female and Male: The Cultic Personnel. The Bible and the Rest of the Ancient Near East. Princeton.

HUSS, W. (1993): Los cartagineses. Madrid.

JIMÉNEZ FLORES, A.M. (2001): "Cultos fenicio-púnicos de Gadir: Prostitución sagrada y Puellae Gaditanae", Habis 32: 11-29.

LAFFINEUR, R. (1988): “Archéologie et religion: Problèmes et méthode”, Kernos 1: 129-140.

LEGLAY, M. (1966): Saturne Africain. Histoire. Paris.

LEVINE, B.A.-TARRAGON, J.M. (1984): "Dead Kings and Rephaïm: the Patrons of the Ugaritic Dinasty", JAOS 104: 649-659. 
LIPINSKI, E. (1987): “Sacrifices d’enfants à Carthage et dans le monde sémitique oriental”, Karthago. Studia Phoenicia VI: 51-185. Leuven.

- (1995): Dieux et Déesses de l'Univers phénicienne et punique. Leiden

MARIOTTI, M.G. (1991): "Templi e sacerdoti a Cartagine”, F. Vattioni ed., Sangue e antropologia nella teologia medievale: 713-736. Roma.

MASSON, O.-SZNYCER, M. (1972): Recherches sur les Phéniciens à Chypre. Paris.

NEGRI SCAFA, P. (2001): "Aspetti del sacerdozio femminile nel Vicino Oriente antico e nel mondo miceneo", S. Ribichini-M. Rocchi-P. Xella dirs., La Questione delle influenze vicino-orientale sulla religione greca: $389-401$. Roma.

OLMO LETE, G. DEL (1995): "La religión cananea de los antiguos hebreos", Mitología y Religión del Oriente Antiguo II/2. Semitas occidentales: 223-250. Barcelona.

OPPENHEIM, L. (1966): "Perspectives on Mesopotamian Divination", La divination en Mésopotamie Ancienne et dans les régions voisines: 35-43. Paris.

PICARD, C. (1973-74): "Les représentations du sacrifice Molk sur les ex-voto de Carthage", Khartago XVII: $67-137$.

PICARD, C.G. (1976): "La Dame des brûle parfums à Carthage", Homenaje a García Bellido I. Revista de la Universidad Complutense XXV, $n^{o} 1: 155-174$. Madrid.

PUECH, E. (1994): "Une cràtere phénicien inscrit: rites et croyances", Trans 8: 47-73.

REY COQUAIS, J.O. (1987): "Sur une comparaison entre le clergé phénicien et le clergé "Africain”, AfRo 5: 397-402. Sassari.

RIBICHINI, S. (1985): “Temple et sacerdoce dans l'économie de Carthage”, Histoire et Archéologie de l'Afrique du Nord. II ${ }^{\text {me }}$ Coll. Int. Grenoble (5-9 aprile 1983): 29-37. Paris.

SZNYCER, M. (1975): "L"'assemblée du peuple" dans les cités puniques d après les témoignages épigraphiques", Semitica 25: 47-68.

VERGER, A. (1965): "Noti di epigrafia punica giuridica I. Matronimici e ierodulia nell Africa punica", RSO 40: 261-265.

XELLA, P. (1985): "Quelques aspects du rapport économie-religion d’après les tarifs sacrificiels puniques", Bulletin Archéologique du C.T.H.S. 19B: 39-47.

XELLA, P.-BONNET, C. (1996): "L'identité d'Astarté ḥr", Alle soglie della Classicittà. Il Mediterraneo tra Tradizione e Innovazione. Studi in onore di S. Moscati I: 29-46. Roma.

YAMAUCHI, E.M. (1973): "Cultic Prostitution", Orient and Occident. Essays Presented to C.H. Gordon (AOAT 22): 213-222. Kevelauer-Neukirchen-Vluyn.

YON, M. (1995): “L'archéologie monumentale partim Orient”, V. Krings ed., La Civilisation Phénicienne et Punique: 119-131. Leiden. 